\title{
The Research Trends of Pharmacopuncture Therapy on Cervical Pain Caused by Traffic Accidents
}

\author{
Dong-young Kim ${ }^{1}$, Seung-hyo Hong ${ }^{1}$, Soo-yeon $\mathrm{Han}^{2}$, Won-young $\mathrm{Kim}^{3}$, Seo-hye $\mathrm{Oh}^{4}$, Hyung-woo Lee ${ }^{5}$, \\ Hyun-su Woo ${ }^{6}$ *
}

Departments of ${ }^{1}$ Acupuncture and Moxibustion Medicine, ${ }^{2}$ Korean Medicine Rehabilitation, ${ }^{3}$ Sasang Constitutional Medicine, ${ }^{4}$ Internal Korean Medicine, ${ }^{5}$ Oriental Neuropsychiatry, Dongseo Korean Medical Hospital, Seoul, Republic of Korea

${ }^{6}$ Kyunghee Dongju Korean Medicine Clinic, Seoul, Republic of Korea

Received November 4, 2020

Reviewed November 5, 2020

Accepted December 4, 2020

*Corresponding Author

Hyun-su Woo

Kyunghee Dongju Korean Medicine Clinic, 50, Arisu-ro 93na-gil, Gangdonggu, Seoul 05201, Republic of Korea Tel: +82-2-428-8891

E-mail: mari10@hanmail.net
Objectives: The purpose of this study is to comprehensively review Korean domestic studies and investigate the research trends of pharmacopuncture therapy on cervical pain caused by traffic accidents.

Methods: Domestic studies between February 1999 and May 2020 from four Korean databases were searched with combinations of keywords 'cervical pain', 'traffic accident', 'whiplash injury', and 'pharmacopuncture'.

Results: 17 studies were selected for review, including 7 randomized controlled trials, 5 retrospective observational studies, 3 case reports, and 2 non-randomized controlled trials. Each study was reviewed by published year, study type, types of pharmacopuncture solutions, selected acupuncture points, dosage of pharmacopuncture solutions, frequency of treatment, concurrent treatments, outcome measurements, and the effectiveness of pharmacopuncture therapy. The results are as follows: (1) It showed that the total number of published studies had increased slightly in the last 10 years compared to the previous decade. (2) The pharmacopuncture solutions used in the studies were in the following order: Bee-Venom (蜂毒), Jungsongouhyul (中性瘀血), Hwangryunhaedoktang (黃連解毒湯) and Soyeom (消炎). Frequently used acupuncture points were GB20, GV21, A-shi point, GV16, EX-B2, and SI15 in order. (3) The most commonly used total injection dosage was $1.0 \mathrm{cc}$ at a time, and the frequency of treatment was twice a week. (4) Concurrent treatments such as acupuncture, herbal medication, physical therapy and Chuna manual therapy were performed in all 17 studies. (5) Pharmacopuncture therapy showed positive effects on cervical pain caused by traffic accidents in all 17 studies reviewed.

Conclusion: Pharmacopuncture therapy was effective in cervical pain caused by traffic accidents in all 17 studies selected. Further studies will be needed using more larger scales and more objective data to confirm the effectiveness of pharmacopuncture therapy and to generalize its application.

Keywords: cervical pain, pharmacopuncture, traffic accident, whiplash injury

\section{INTRODUCTION}

As the economy rapidly grow up recently, road traffic has increased. As automobiles became a major means of transportation traffic accidents is increasing every year. According to statistics of traffic accident trend from the Korea ROAD Traffic Authority in 2019, the number of traffic accidents increased from 2018 by $5.73 \%$ compared to that in 2019 229,600, the number of deaths decreased by $11.42 \% 3,349$, but the number of injured increased by $5.78 \% 341,712$. As injuries from traffic accidents increases, management of injuries and aftereffects has become an important issue [1].

In the case of critical patients with trauma, such as brain damage, massive bleeding and fractures caused by traffic ac- 
cidents, first aid of Western medicine should be considered first to treat these emergencies; but, for patients with minor injuries who does not require surgical treatment, Korean medical treatment can be an alternative option [2]. Ever since 1999 auto insurance coverage included Korean medical treatment and the number of patients receiving Korean medical treatment and the proportion of Korean medicine expenses among total medical expenses of automobile insurance is continuously increasing. Because of the diversity, uniqueness and efficiency of Korean medicine, patients are highly satisfied [3].

The most common symptom resulted from traffic accidents is pain in the cervical region including whiplash injury. Whiplash injury is a syndrome that causes damage to soft tissues of neck due to hyperextension and subsequent flexion of the head and neck from rear-end collisions, resulting in various symptoms including neck pain [4].

In Korean medical treatments, acupuncture, herbal medication, pharmacopuncture, and Chuna manual therapy are commonly used to treat cervical pain caused by whiplash injury. Pharmacopuncture is a new form of therapy that combines acupuncture theory and herbal medicine theory. This method treats diseases by injecting medicinal fluid including specific herb extracts into meridian and surface reaction points [5].

The purpose of this study is to understand the effects of pharmacopuncture and help to expand the application of pharmacopuncture by reviewing Korean domestic studies that use pharmacopuncture therapy on cervical pain caused by traffic accidents after 1999.

\section{MATERIALS AND METHODS}

\section{Databases and search method}

Studies were searched from four databases: Research Information Sharing Service (RISS), Koreanstudies Information Service System (KISS), Oriental Medicine Advanced Searching Integrated System (OASIS), and National Digital Science Library (NDSL), combining the keywords of 'cervical pain', 'traffic accident,' 'whiplash injury' and 'pharmacopuncture'.

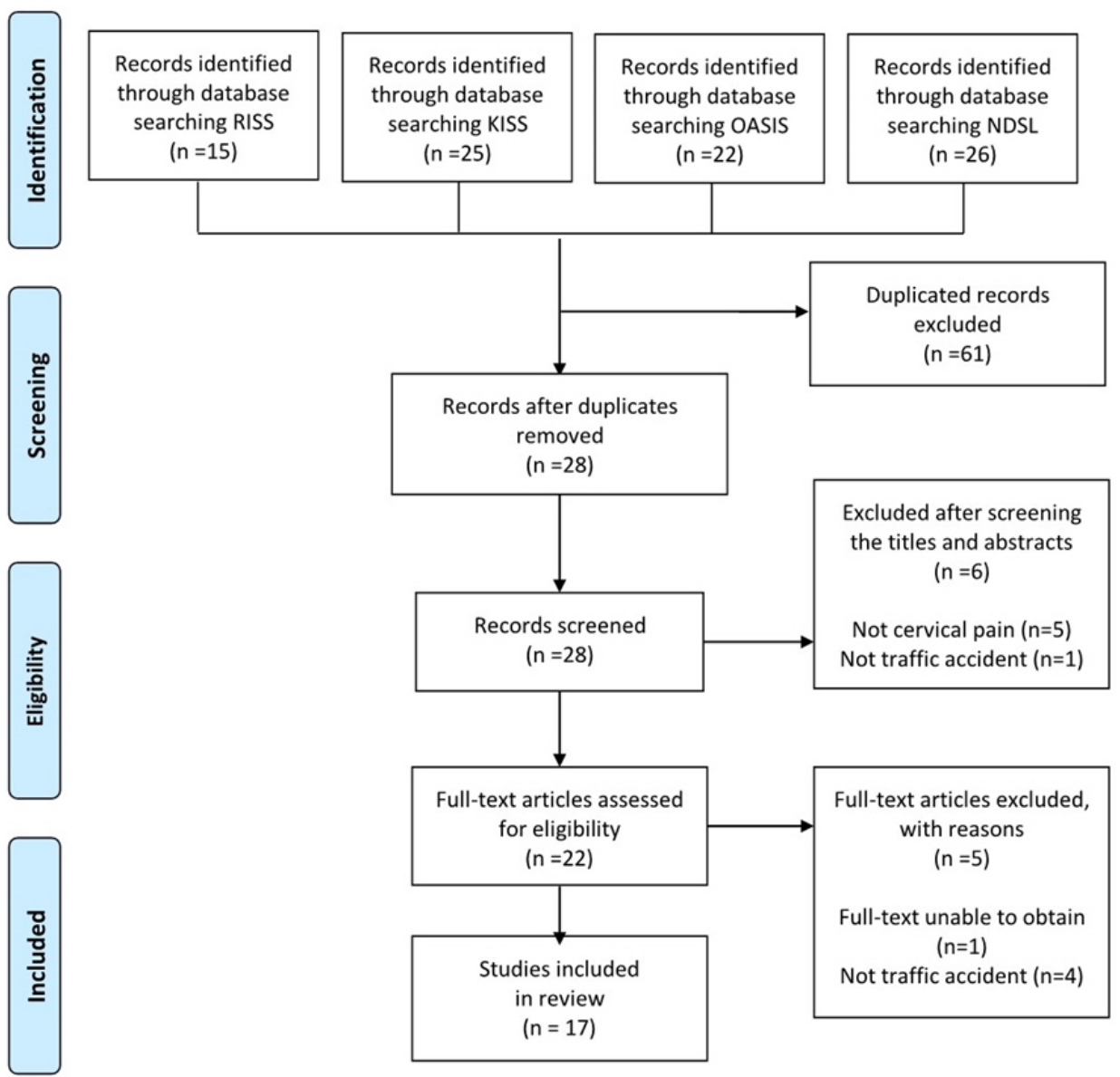

Figure 1. Flow chart of study selection. 
The Research Trends of Pharmacopuncture Therapy on Cervical Pain Caused by Traffic Accidents

Table 1. Characteristic of treatment in each study

\begin{tabular}{|c|c|c|c|c|c|c|c|c|}
\hline $\begin{array}{l}\text { 1st author } \\
\text { (year) }\end{array}$ & $\begin{array}{l}\text { Study } \\
\text { design }\end{array}$ & $\begin{array}{l}\text { Sub- } \\
\text { jects }\end{array}$ & $\begin{array}{c}\text { Type of } \\
\text { pharmacopuncture } \\
\text { solutions }\end{array}$ & $\begin{array}{l}\text { Acupuncture } \\
\text { points }\end{array}$ & $\begin{array}{l}\text { Total dosage/ } \\
\text { dosage per } \\
\text { acupuncture } \\
\text { point }\end{array}$ & $\begin{array}{l}\text { Time of } \\
\text { treatment/ } \\
\text { frequency of } \\
\text { treatment }\end{array}$ & $\begin{array}{l}\text { Concurrent } \\
\text { treatment }\end{array}$ & $\begin{array}{l}\text { Outcome } \\
\text { measures }\end{array}$ \\
\hline $\begin{array}{l}\text { Park KB } \\
\text { (2005) [6] }\end{array}$ & $\mathrm{nRCT}$ & 33 & Bee-Venom & $\begin{array}{l}\text { GV16, GB20, } \\
\text { GB12, GV15 }\end{array}$ & $\begin{array}{l}0.2-1.0 \mathrm{cc} / \\
0.1 \mathrm{cc}\end{array}$ & $\begin{array}{l}\text { Uncertain/ } \\
3 \text { times a week }\end{array}$ & A-Tx., P-Tx. & VAS, Grade \\
\hline $\begin{array}{l}\text { Seol H } \\
\text { (2005) [7] }\end{array}$ & $\mathrm{nRCT}$ & 48 & Jungsongouhyul & EX-B2, A-shi point & $\begin{array}{l}1.0 \mathrm{cc} / \\
0.02-0.03 \mathrm{cc}\end{array}$ & $\begin{array}{r}\text { Uncertain/ } \\
\text { everyday }\end{array}$ & $\begin{array}{l}\text { A-Tx., H-med, } \\
\text { P-Tx. }\end{array}$ & VAS, Grade \\
\hline $\begin{array}{l}\text { Kim KH } \\
\text { (2006) [8] }\end{array}$ & $\mathrm{CR}$ & 21 & Bee-Venom & $\begin{array}{l}\text { BL10, GB20, } \\
\text { GV21, SI14, } \\
\text { SI15, SI13, SI11 }\end{array}$ & $\begin{array}{l}0.7 \mathrm{cc} / \\
0.1 \mathrm{cc}\end{array}$ & 8/twice a week & A-Tx. & VAS, SF-36 \\
\hline $\begin{array}{l}\text { Chang SY } \\
\text { (2007) [9] }\end{array}$ & ROS & 44 & $\begin{array}{l}\text { Carthami-flos seeds \& } \\
\text { Juglandis semen }\end{array}$ & A-shi point & $\begin{array}{l}0.4 \mathrm{cc} / \\
0.07-0.1 \mathrm{cc}\end{array}$ & $\begin{array}{l}\text { 3-6/ } \\
\text { uncertain }\end{array}$ & $\begin{array}{l}\text { A-Tx., H-med, } \\
\text { P-Tx. }\end{array}$ & VAS, ROM \\
\hline $\begin{array}{l}\text { Woo JH } \\
\qquad(2011)[12]\end{array}$ & $\mathrm{RCT}$ & 60 & Jungsongouhyul & A-shi point & $\begin{array}{l}1.0 \mathrm{cc} / \\
\text { uncertain }\end{array}$ & 4/twice a week & A-Tx. & VAS, NDI \\
\hline $\begin{array}{l}\text { Lee SJ } \\
\qquad(2011) \text { [13] }\end{array}$ & $\mathrm{CR}$ & 10 & Bee-Venom & Facet joint & $\begin{array}{r}0.1-2.0 \mathrm{cc} / \\
\text { uncertain }\end{array}$ & 8/uncertain & A-Tx. & NRS, NDI \\
\hline $\begin{array}{l}\text { Lee JH } \\
\qquad(2012)[14]\end{array}$ & RCT & 82 & Hwangryunhaedoktang & $\begin{array}{l}\text { GV16, GB20, } \\
\text { GV21 }\end{array}$ & $\begin{array}{l}1.0 \mathrm{cc} / \\
\text { uncertain }\end{array}$ & 8/twice a week & A-Tx., H-med & VAS, NDI \\
\hline $\begin{array}{l}\text { Lim GM } \\
\qquad(2012) \text { [15] }\end{array}$ & RCT & 26 & $\begin{array}{l}\text { Soyeom, } \\
\text { Jungsongouhyul }\end{array}$ & $\begin{array}{l}\text { EX-B2, A-shi point, } \\
\text { GB20, GV21, } \\
\text { GV14 }\end{array}$ & $\begin{array}{l}1.0 \mathrm{cc} / \\
0.05-0.1 \mathrm{cc}\end{array}$ & $\begin{array}{l}\text { 5/every other } \\
\text { day }\end{array}$ & $\begin{array}{l}\text { A-Tx., H-med, } \\
\text { P-Tx., CMT }\end{array}$ & $\begin{array}{r}\text { VAS, NDI, } \\
\text { SF-MPQ }\end{array}$ \\
\hline $\begin{array}{l}\text { Kim KW } \\
\text { (2014) [18] }\end{array}$ & ROS & 59 & Shinbaro, Bee-Venom & Trigger point & $\begin{array}{l}1.0 \mathrm{cc} / \\
0.1-0.3 \mathrm{cc}\end{array}$ & 6/twice a week & A-Tx., H-med & NRS, NDI \\
\hline $\begin{array}{l}\text { Lee YC } \\
\qquad(2014)[19]\end{array}$ & $\mathrm{RCT}$ & 40 & $\begin{array}{l}\text { Hwangryunhaedoktang, } \\
\text { Essential Bee-Venom }\end{array}$ & GV21, GB20, SI15 & $\begin{array}{l}1.0 \mathrm{cc} / \\
0.1-0.2 \mathrm{cc}\end{array}$ & $\begin{array}{l}\text { 3/every other } \\
\text { day }\end{array}$ & $\begin{array}{l}\text { A-Tx., H-med, } \\
\text { P-Tx. }\end{array}$ & $\begin{array}{l}\text { VAS, NDI, } \\
\text { pain } \\
\text { threshold }\end{array}$ \\
\hline $\begin{array}{l}\text { Choi JW } \\
\qquad(2015) \text { [20] }\end{array}$ & $\mathrm{CR}$ & 1 & Hwangryunhaedoktang & $\begin{array}{l}\text { EX-B2, GV21, } \\
\text { GB20, Facet } \\
\text { joint (C6-T1) }\end{array}$ & $\begin{array}{l}2.0 \mathrm{cc} / \\
\text { uncertain }\end{array}$ & 7/twice a week & $\begin{array}{c}\text { A-Tx., H-med, } \\
\text { P-Tx., CMT }\end{array}$ & VAS, NRS \\
\hline $\begin{array}{l}\text { Han KI } \\
\text { (2016) [21] }\end{array}$ & ROS & 39 & $\begin{array}{l}\text { Muscle relaxation } \\
\text { pharmacopuncture } \\
\text { (JS5-MR, } \\
\text { Jakyakgamchotang) }\end{array}$ & $\begin{array}{r}\text { GV16, GB20, } \\
\text { GV21, SI15 }\end{array}$ & $\begin{array}{l}0.8 \mathrm{cc} / \\
0.1-0.2 \mathrm{cc}\end{array}$ & $\begin{array}{l}\text { Uncertain/ } \\
3 \text { times a week }\end{array}$ & $\begin{array}{l}\text { A-Tx., H-med, } \\
\text { P-Tx. }\end{array}$ & VAS, NDI \\
\hline $\begin{array}{l}\text { Kim YJ } \\
\qquad(2018)[22]\end{array}$ & ROS & 52 & $\begin{array}{l}\text { Hwangryunhaedoktang, } \\
\text { Bee-Venom, } \\
\text { Jungsongouhyul }\end{array}$ & Trigger point & $0.6 \mathrm{cc} / 0.1 \mathrm{cc}$ & $\begin{array}{l}\text { Uncertain/ } \\
\text { every day }\end{array}$ & $\begin{array}{l}\text { A-Tx., H-med, } \\
\text { P-Tx. }\end{array}$ & NDI, PGA \\
\hline
\end{tabular}

Abbreviations: nRCT, non-randomized controlled trial; A-Tx., acupuncture treatment; P-Tx., physical treatment; VAS, visual analog scale; H-med, Herbal medication; CR, case report; SF-36, 36-Item Short-form Health Survey; ROS, retrospective observational study; ROM, range of motion; RCT, randomized controlled trial; NDI, neck disability index; DITI, digital infrared thermal imaging; CMT, Chuna manual therapy; SF-MPQ, Short-form McGill Pain Questionnaire; PGA, patient's global assessment. 


\section{Study selection and eligibility criteria}

Clinical studies published in Korean domestic journals related to Korean medicine from February 1999 to May 2020 were selected. Literature reviews, animal experiments, and laboratory experiments were excluded. Studies focused on systemic symptoms other than cervical pain and studies in which traffic accident is not the cause of cervical pain were also excluded. Studies in which pharmacopuncture performed to improve cervical pain included, even if pharmacopuncture and other types of treatment performed concurrently.

The selection of studies was based on the title and the abstract, and if necessary the original texts were reviewed to make a final selection.

\section{RESULTS}

89 clinical studies were retrieved from February 1999 to May 2020 from four Korean databases and 28 studies were initially selected. After excluding 61 duplicate studies, 11 studies were excluded by screening the titles, abstracts, and full texts, and 17 studies sere finally selected for this review (Fig. 1, Table 1) [6-22].

\section{Published year}

Between 1999 and 2020, studies were steadily published. In 2011 and 2012, 3 studies were published each, 2 studies were published in 2005 and 2014 each, and 1 in 2006, 2007, 2015 and 2016 each (Fig. 2).

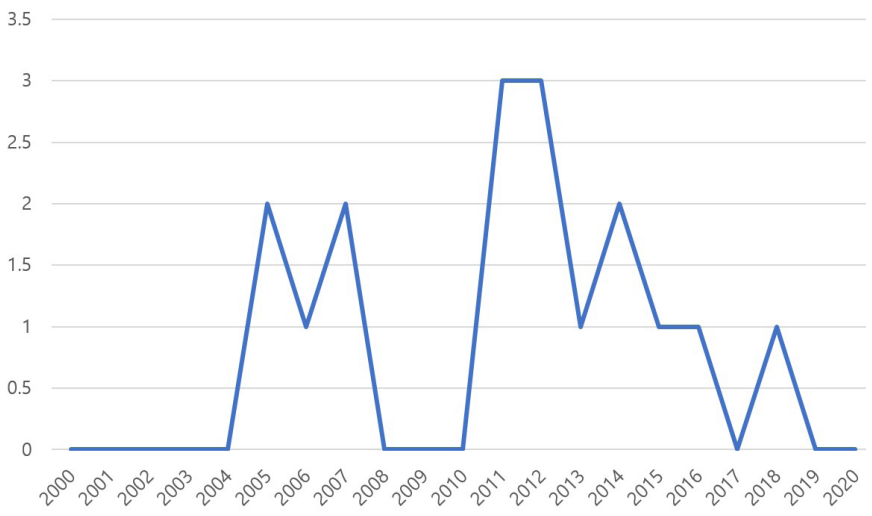

Figure 2. Published year.
2. Type of study

Of the 17 studies, 7 randomized controlled trials (RCT) (41.2\%), 5 retrospective observational studies (29.4\%), 3 case reports (CR) (17.6\%) (Fig. 3) and 2 non-randomized controlled trials (nRCT) (11.8\%) (Fig. 3).

\section{Types of pharmacopuncture solutions and acupuncture points}

\section{1) Types of pharmacopuncture solutions}

The most commonly used pharmacopuncture solution was Bee-Venom (蜂毒) which was used in 7 studies (30.4\%). Jungsongouhyul (中性瘀血) and Hwangryunhaedoktang (黃連解毒 湯) used in 5 studies (21.7\%) each, Soyeom (消炎) and Shinbaro in 2 studies (8.7\%) each, and Carthami-flos seeds \& Juglandis semen (紅花 \& 胡桃) and Muscle Relaxation pharmacopuncture (JS5-MR) in 1 study (4.3\%) each (Table 2). 12 studies used only one type of pharmacopuncture solution (70.6\%), 4 studies used two kinds of pharmacopuncture solutions (23.5\%), and 1 study used three kinds of pharmacopuncture solutions (5.9\%) (Fig. 4).

\section{2) Acupuncture points}

The acupuncture points used in the studies included GV16, GB20, GB12, GV15, BL11, GV21, SI14, SI15, SI13, SI11, and

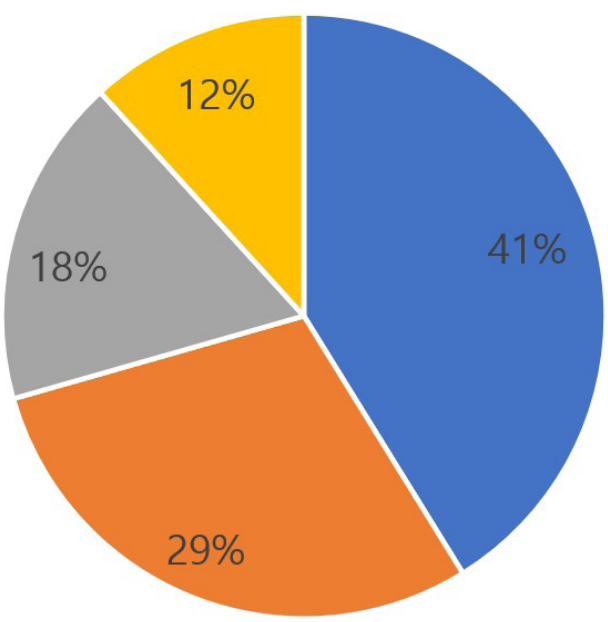

- RCT - retrospective observational study $\| \mathrm{CR} \quad$ nRCT

Figure 3. Type of study. Abbreviations: RCT, randomized controlled trial; $\mathrm{CR}$, case report; $\mathrm{nRCT}$, non-randomized controlled trial. 
Table 2. Types of pharmacopuncture

\begin{tabular}{lcc}
\hline \multicolumn{1}{c}{ Pharmacopuncture } & No. & Percent (\%) \\
\hline Bee-Venom & 7 & 30.4 \\
Jungsongouhyul & 5 & 21.7 \\
Hwangryunhaedoktang & 5 & 21.7 \\
Soyeom & 2 & 8.7 \\
Shinbaro & 2 & 8.7 \\
Carthami-flos seeds \& Juglandis semen & 1 & 4.3 \\
Muscle Relaxation (JS5-MR) & 1 & 4.3 \\
\hline
\end{tabular}

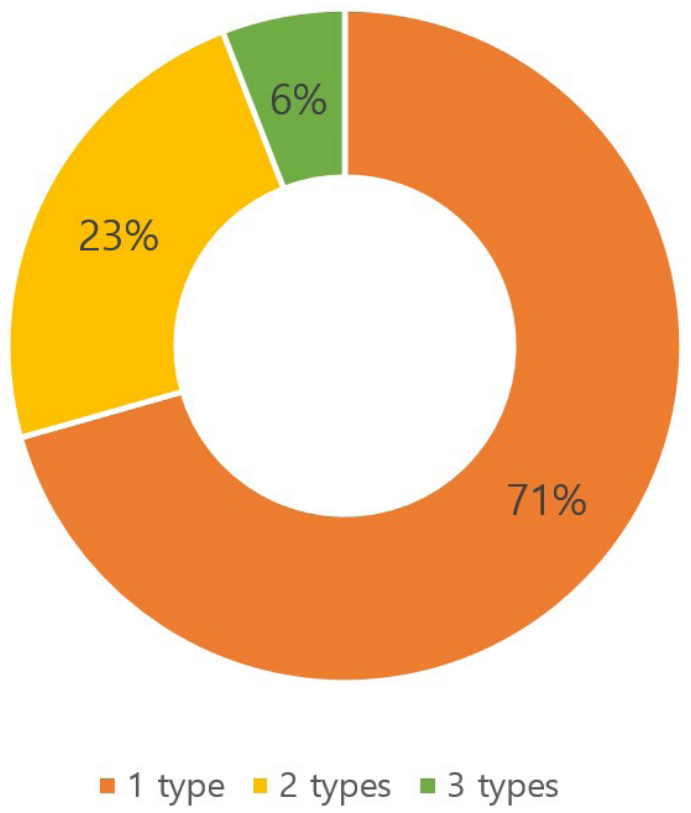

Figure 4. Number of types of pharmacopuncture solutions.

GV14, in addition to EX-B2, A-shi point, trigger point, and facet joint. The number of acupuncture points used in the studies varied. Of the studies, 10 studies which mentioned acupuncture points as A-shi point, trigger point, and facet joint could not accurately determine the location and number of acupuncture points.

The most commonly used acupuncture point was the GB20, which was used in 10 studies (19.6\%), followed by GV21 in 9 (17.6\%), A-shi point in 6 (11.8\%), GV16, EX-B2 and SI15 in 4 (7.8\% each), trigger point in 3 (5.9\% each), SI14, GV14, and facet joint in 2 (3.9\% each), GB12, GV15, BL10, SI13, SI11 in 1 (2\% each) (Table 3$)$.
Table 3. Used acupuncture points

\begin{tabular}{|lcc}
\hline Acupuncture point & No. & Percent (\%) \\
\hline GB20 & 10 & 19.6 \\
\hline GV21 & 9 & 17.6 \\
\hline A-shi point & 6 & 11.8 \\
\hline GV16 & 4 & 7.8 \\
\hline EX-B2 & 4 & 7.8 \\
\hline SI15 & 4 & 7.8 \\
\hline Trigger point & 3 & 5.9 \\
\hline SI14 & 2 & 3.9 \\
\hline GV14 & 2 & 3.9 \\
Facet joint & 2 & 3.9 \\
GB12 & 1 & 2.0 \\
GV15 & 1 & 2.0 \\
\hline BL10 & 1 & 2.0 \\
SI13 & 1 & 2.0 \\
\hline SI11 & 1 & 2.0 \\
\hline
\end{tabular}

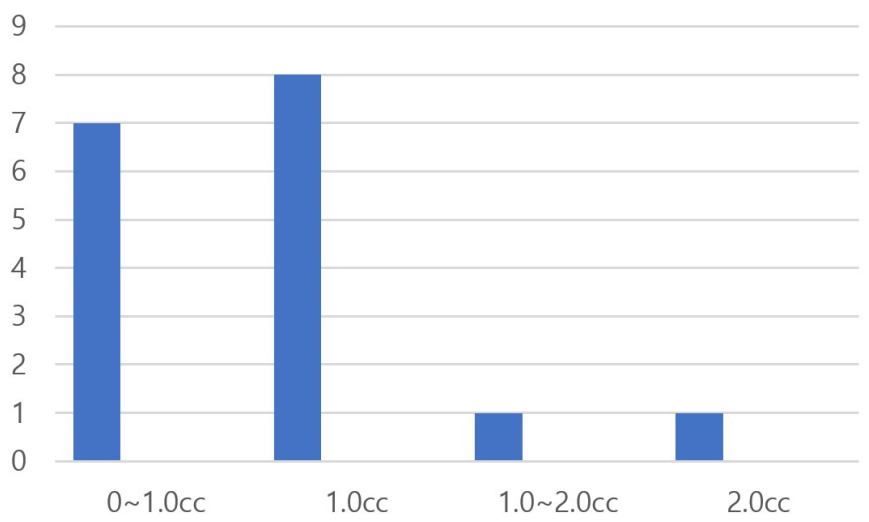

Figure 5. Total dosage of pharmacopuncture.

\section{Dosage of pharmacopunctue solutions and frequency of treatment}

\section{1) Dosage of injected pharmacopuncture solutions}

The total dosage of injected pharmacopuncture solutions in each case was mentioned in all 17 studies. In 7 studies (41.2\%) less than $1.0 \mathrm{cc}$, in 8 (47.0\%) $1.0 \mathrm{cc}$ was used, and the other 2 studies (5.9\% each) used $1.0 \mathrm{cc}-2.0 \mathrm{cc}$, and $2.0 \mathrm{cc}$ each (Fig. 5, Table 1).

The dosage of pharmacopuncture solutions injected into each acupuncture point was mentioned in 12 studies. There were 4 studies (23.5\%) used less than $0.1 \mathrm{cc}, 4(23.5 \%)$ used 0.1 cc, and $4(23.5 \%)$ used over 0.1 cc. 5 studies (29.4\%) that did 
not mention the dosage of pharmacopuncture injected at each acupuncture points.

\section{2) Number and frequency of treatment}

Except 5 studies (29.4\%) with no specific mention of the number of treatments, 4 studies practiced 8 times of treatment times (23.5\%), 3 studies 5 times (17.6\%), 2 studies 6 times (11.8\%), and there were 3 studies in which 3, 4 and 7 times of treatment were performed each (5.9\%).

The frequency of treatment was twice a week in 7 studies (41.2\%), every other day in 3 studies (17.6\%), and three times a week and every day in 2 studies ( $11.8 \%$ each). There were 3 studies (17.6\%) without any mention of specific treatment frequency (Fig. 6, Table 1).

\section{Concurrent treatments}

Concurrent treatments such as acupuncture, herbal medication, physical therapy and Chuna manual therapy were performed in all 17 studies. Acupuncture treatment has been used in all studies (100\%). Other main concurrent treatments were herbal medication and physical therapy. There were 9 studies $(52.9 \%)$ in which all three treatments above were used (Table 1).

\section{Outcome measures to assess pain improvement}

Among the 17 studies, 14 studies (82.4\%) used two types of outcome measures and 3 studies (17.6\%) used three types of outcome measures. There were 9 outcome measures used in the studies: Visual analog scale (VAS), Neck disability index (NDI), Range of motion (ROM), Numeral rating scale (NRS), Grade

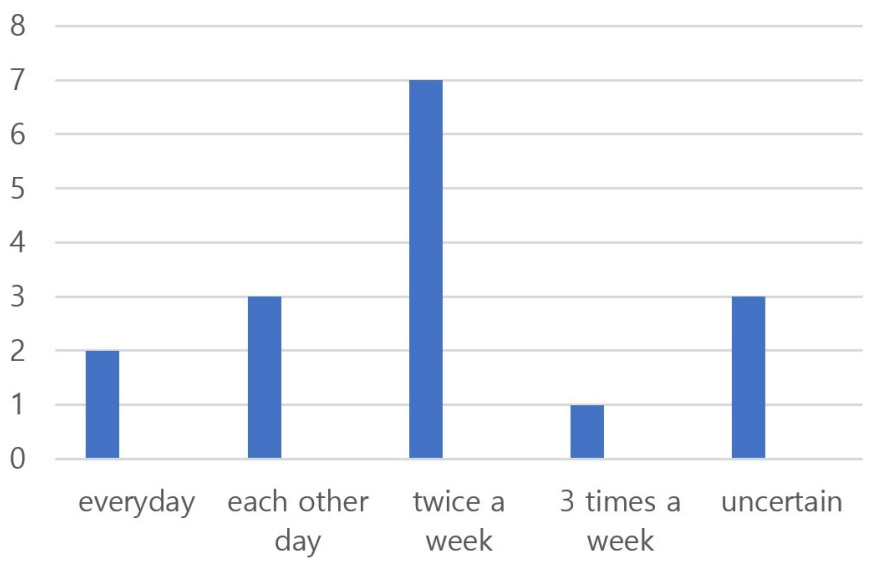

Figure 6. Frequency of pharmacopuncture therapy.
(Gr), Short-Form (SF), Digital infrared thermal imaging (DITI), Pain threshold, and Patient's global assessment (PGA). The most frequently used criteria were VAS, which was used in 14 studies $(37.8 \%)$, followed by NDI in 11 (29.7\%). NRS was used 3 times (8.1\%), ROM, NRS, Grade, and Short-Form used twice each (5.4\% each), and DITI, Pain threshold and PGA were each used in single time (2.7\% each) (Table 1$)$.

\section{Effectiveness of pharmacopuncture}

All 17 studies showed significant improvements in cervical pain after pharmacopuncture treatment.

\section{1) Effectiveness of each pharmacopuncture solution}

Park et al [6], Kim et al [8], Song [10], Lee et al [13], Seol et al [7], Chang et al [9], and Im et al [11] looked at the effects of each pharmacopuncture solution on cervical pain caused by traffic accidents. Among them, Park et al [6], Kim et al [8], Song [10], Lee et al [13] reported Bee-Venom pharmacopuncture (蜂毒藥鍼) was effective for treating cervical pain. Park et al [6] reported that in the group that received Bee-venom pharmacopuncture therapy, the average response-to-treatment time was shorter than the acupuncture group, and the clinical evaluation grade also showed better results. In the study by Kim et al [8], there were significant improvements in VAS score and some categories in the 36-Item Short-form Health Survey (SF-36) questionnaire. In the study by Song [10], after 5 treatments, VAS decreased more in the Sweet Bee-Venom pharmacopuncture group than in the normal saline group, and there was a significant improvement of the range of motion (ROM) of the cervical spine. Lee et al [13] reported that 10 patients were treated with cervical acupuncture and cervical facet joint Bee-Venom pharmacopuncture, and clinical symptoms were improved and NRS scores decreased afterwards. Other types of pharmacopuncture have also been reported to be effective. In the study by Seol et al [7], Jungsongouhyul pharmacopuncture (中性瘀血藥鍼) was effective to treat cervical pain. Compared to the acupuncture group, the VAS decreased significantly in the group that received acupuncture and Jungsongouhyul pharmacopuncture concurrently. In the study by Chang et al [9], the acupuncture group was compared with the group that received acupuncture and Carthami-flos seeds and Juglandis semen pharmacopuncture (紅花\&胡桃藥鍼) concurrently. The result showed that the group with acupuncture and pharmacopuncture was more effective to improve VAS and ROM. In a study 
by Im et al [11], in the Soyeom pharmacopuncture (消炎藥鍼) group, change of the VAS and the Neck Disability Index (NDI) was more significant.

\section{2) Comparison between different types of pharmacopuncture solutions}

Studies by Lim et al [15], Kim et al [17], Kim et al [18], Lee et al [19], and Kim et al [22] compared different types of pharmacopuncture solutions. In the study by Lim et al [15], patients were divided into two groups: Jungsongouhyul pharmacopuncture group and Soyeom pharmacopuncture group. Both groups showed statistically significant improvement on the outcome measure before and after treatment. In the study by Kim et al [17], the Shinbaro group showed a swifter decline than the Junsongouhyul group in both VAS and NDI scores. In the study by Kim et al [18], Shinbaro pharmacopuncture group and Bee-Venom pharmacopuncture group both showed a significant decrease in NRS and NDI. In addition, it is suggested that Shinbaro pharmacopuncture group is more effective in reducing pain in the earlier period of treatment. In the study by Lee et al [19], there was a significant decrease of VAS, NDI and improvement of pain threshold in both Hwangryunhaedoktang pharmacopuncture (黃連解毒湯藥鍼) group and Essential BeeVenom group. In the study by Kim et al [22], patients were classified into three groups by which pharmacopuncture was used as Hwangryunhaedoktang pharmacopuncture group, BeeVenom pharmacopuncture group, and Jungsongouhyul pharmacopuncture group. Each pharmacopuncture treatment group showed a significant decrease of NDI and PGA. However, in all of the above 5 studies, no statistically significant difference was found in the comparison of effects between the two or three different pharmacopuncture groups.

\section{3) Comparison between pharmacopuncture therapy and}

\section{Chuna manual therapy}

There have been studies comparing pharmacopuncture as well as Chuna manual therapy or pharmacopuncture-Chuna treatment. In the study by Woo et al [12], the improvements in the group that received acupuncture and Chuna manual therapy concurrently and in the group that received acupuncture and Jungsongouhyul pharmacopuncture concurrently were compared. Significant improvements were seen in both groups, but there were no significant differences in improvements between the two groups. In the study by Lee et al [14], Chuna manual therapy and Hwangryunhaedoktang pharmaco- puncture were compared to each other. For the first two weeks, both were effective, but in 2 to 4 weeks Chuna manual therapy was more effective based on VAS scores. In the study by Lee et al [16], patients were divided into three groups: groups treated with Jungsongouhyul pharmacopuncture, Chuna manual therapy, and pharmacopuncture-Chuna cooperative tratment. In result, each group showed a significant improvement in VAS and NDI after 4 weeks later, but especially pharmacopunctureChuna group showed a significant difference as compared to the other groups. In the study by Choi et al [20], a 35-year-old female patient who complained of post neck pain and both arm numbness was treated with Korean medical treatments, including Chuna manual therapy and pharmacopuncture therapy, and the results were found to be effective. In a study by Han et al [21], the effects of Muscle relaxation pharmacopuncture (JS5$\mathrm{MR}$ ) and Chuna manual therapy were compared. In result, each group had significant effects in reducing neck pain, but pharmacopuncture was more effective in reducing NDI.

\section{DISCUSSION}

Whiplash injury is a term for compound damage caused by a sudden acceleration and deceleration from a collision in a traffic accident. The head and neck experiences instant hyperextension followed by flexion, causing damages to muscles around the neck, anterior longitudinal ligament, and annulus fibrosus [23]. The major symptoms of whiplash injury are cervical pain (88-100\%) and headache (54-66\%). Neck stiffness, shoulder pain, numbness in upper extremities with pain, and weakness of upper extremities are also commonly companied [24]. Among symptoms above, sprain and strains in the cervical vertebrae takes the largest portion [25]. Patients often feel pain even though examinations do not show any particular abnormalities [26].

The cervical vertebra consists of 7 vertebrae, and muscles, ligaments and intervertebral discs connect them making cervical vertebrae are capable of flexion, extension, lateral bending and rotational motion [4]. The cervical vertebrae structurally represent C-shaped curve, but upright position causes heavy weight load, and makes it mechanically worn out easily [27].

Also, there are many pain-sensitive tissues in the cervical region such as epithelial tissue, muscle tissue, nerve tissue, and connective tissue. This is also the area where functional damage to the musculoskeletal system is generally likely to occur. The connective tissue is important for structural integration and 
normal function, and arrangement of cell tissues determines its function. Incorrect structural arrangements impair functions and cause incongruous conditions to cause pain [28].

In Korean medicine, acute damage to soft tissue in cervical region can be understood in the category of Stiff neck (項强, 落枕), Neck pain (項痛), Sprain (捻挫傷), Bruise (打撲, 跌撲), Blood stasis (血結), and Cervical disease (頸椎病). Treatments including acupuncture moxibustion therapy, herbal medicine therapy, traction therapy, physical therapy, and pharmacopuncture therapy, focus on ways to relieving pain by improving blood flow, relaxing muscles, and smoothening joints [29].

Among them, pharmacopuncture is a unique treatment combined with meridian theory and the properties-flavors theory of herbal therapy, which has advantages of inserting needles and injecting medicinal fluid directly on lesion area at the same time [30]. Various studies are being conducted using different types of pharmacopuncture solutions in treating cervical pain caused by traffic accidents. It has been reported that Soyeom (消炎) [11, 15], Bee-Venom (蜂毒) [6, 8, 10, 13, 18, 19, 22], Jungsongouhyul (中性瘀血) [7, 12, 15, 17], Carthami-flos seeds \& Juglandis semen (紅花\&胡桃) [9], Hwangryunhaedoktang (黃連解毒湯) [14, 16, 19, 20, 22], Muscle relaxation pharmacopuncture (JS5-MR) [21], and Shinbaro [17, 18] pharmacopuncture have significant therapeutic effects.

In this regard, this study was intended to review Korean domestic studies using pharmacopuncture therapy on cervical pain caused by traffic accidents, since the Automobile Damage Compensation Act' was revised in February 1999.

Selected 17 studies were published between 2005 and 2018, with the most frequent number of publications being 3 in 2011 and 2012. The total number of studies published between 2000 and 2009 was 5 while between 2010 and 2019 it was 12, indicating that the number of studies using pharmacopuncture in treating cervical pain caused by traffic accidents has more than doubled over the past decade. Of the studies, 7 were RCT (41.2\%), 5 were retrospective observational study (29.4\%), 3 were clinical CR (17.6\%) and 2 were non-RCT (11.8\%). The most commonly used pharmacopuncture solution was BeeVenom, accounting for $30.4 \%$. Next, Jungsongouhyul and Hwangryunhaedoktang accounted for $21.7 \%$ each, Soyeom and Shinbaro accounted for $8.7 \%$ each, and Carthami-flos seeds \& Juglandis semen and Muscle relaxation pharmacopuncture (JS5-MR) accounted for $4.3 \%$ each.

Bee-Venom pharmacopuncture (蜂毒藥鍼) is a medicinal solution that has been purified with electrical stimulation ex- tracting poison. It has an effect of expelling pathogenic wind and eliminating dampness, relieving pain, relieving asthma (spasmolysis), subsiding of swelling and reducing blood pressure [31]. Also, Sweet Bee-Venom pharmacopuncture was made by removing enzymes known as allergy antigens from the Bee-Venom, which is known to be effective in reducing edema, itching, pain, etc., of the treatment area and preventing anaphylaxis compared to Bee-Venom [32].

Jungsongouhyul pharmacopuncture (中性瘀血藥鍼) is composed of medicinal herbs that remove blood stasis, which includes such as Gardeniae Fructus, Corydalis Tuber, Olibanum, Myrrha, Persicae Semen, Paeoniae Radix Rubra, Salviae Miltiorrhizae Radix, Sappan Lignum. It is used for all kinds of pain such as cervical pain from whiplash injury, because of its blood circulation promoting, blood stasis removing, and pain-relieving effects [5].

Hwangryunhaedoktang pharmacopuncture (黃連解毒湯藥 鍼) is composed of Scutellariae Radix, Coptidis Rhizoma, Phellodendri Cortex, Gardeniae Fructus, and has an anti-inflammatory, spasmolytic, heat clearing and pain-relieving effect [33].

Soyeom pharmacopuncture (消炎藥鍼) is composed of pain reducers, such as Taraxaci Herba, Lonicerae Flos, Rehmanniae Radix, Forsythiae Fructus, Scutellariae Radix, Coptidis Rhizoma, Phellodendri Cortex, and Gardeniae Fructus, which can be used for pain relief and infection control purposes for acute inflammation and pain diseases [34].

Shinbaro pharmacopuncture is produced by adding and subtracting medicinal herbs of Cheongpa-jeon (GCSB-5) [35], a unique prescription of Jaseng Hospital of Korean Medicine. This has the effect of promoting blood circulation and removing blood stasis to relieve pain, resolve dampness and subside swelling, and strengthen muscles and bones of patients with cervical pain.

Carthami-flos is known as an herb essential to promoting blood circulation and removing blood stasis. Clinical studies have confirmed that the Carthami-flos seeds pharmacopuncture (紅花藥鍼) has a valid effect on the recovery of cervical pain or low back pain. Juglandis semen has the effect of circulating blood vessels and softening bones and muscles. An experimental report has been released on the pain effects of the Juglandis semen pharmacopuncture (胡桃藥鍼) [9].

Muscle Relaxation pharmacopuncture (JS5-MR) is made by diluting the powder of 'Jakyakgamchotang' (菏藥甘草湯), which is known to be effective for pain and anti-convulsions [36].

Commonly used acupuncture points in the studies were in 
the following order: GB20 10 times, GV21 9 times, A-shi point 6 times, GV16, EX-B2, SI15 4 times each, trigger point 3 times, SI14, GV14, facet joint 2 times each, and GB12, GV15, BL10, SI13, SI11 1 time each. In regards to the dosage of pharmacopuncture, in 8 studies $1.0 \mathrm{cc}$ was used, in 7 studies less than $1.0 \mathrm{cc}$ was used, and in the other 2 studies $1.0-2.0 \mathrm{cc}$ and $2.0 \mathrm{cc}$ were used, respectively. With respect to the frequency of pharmacopuncture treatments, in 7 studies pharmacopuncture was practiced twice a week, in 3 studies every other day, 2 studies three times a week, and the other 2 studies every day.

Two or three measurements were used to evaluate outcome. The most frequently used one was VAS, which was used in 14 studies, followed by NDI used in 11. In addition, NRS, ROM, Grade, Short-Form, DITI, Pain Threshold and PGA were also used.

In all the selected studies for review, pharmacopuncture therapy was performed with other Korean medical treatments such as acupuncture, herbal medication, physical therapy, and Chuna manual therapy. Pharmacopuncture treatment was effective to a certain degree in all 17 studies. Before and after pharmacopuncture treatment, patients' pain level was improved, and statistically significant results were found.

The results above confirm that all Bee-Venom (蜂毒), Jungsongouhyul (中性瘀血), Hwangryunhaedoktang (黃連解毒 湯), Soyeom (消炎), Shinbaro, Carthami-flos seeds \& Juglandis semen (紅花\&胡桃藥鍼), and Muscle Relaxation pharmacopuncture (JS5-MR), have effects in improving pain, ROM, and degree of disability in daily lives of patients with cervical pain caused by traffic accidents.

This study has some limitations. First, it is difficult to generalize the efficacy of pharmacopuncture to all patients involved in traffic accidents due to the small size and number of studies. Second, it is difficult to confirm the efficacy of pharmacopuncture itself because there are other concurrent treatments such as acupuncture, herbal medication, and physical therapy. Third, there was no difference between each pharmacopuncture group because the same pharmacopuncture solutions were used without differentiating between each patient's pattern and the number of days elapsed since the date of the accident. Based on the results of this study, future investigations will be needed to evaluate the effect of pharmacopuncture therapy on cervical pain due to traffic accidents by expanding the size of the subjects and referencing more objective studies. Also, this study only targeted domestic studies in Korea, there is a limit to the numbers of data, so it would be better to include international studies in the future.

\section{CONCLUSION}

The following conclusions were obtained from the review of the 17 clinical studies selected from the Korean domestic databases (RISS, KISS, OASIS, NDSL), in which pharmacopuncture was performed to treat cervical pain caused by traffic accidents.

Pharmacopuncture therapy was effective in cervical pain caused by traffic accidents in all 17 studies selected. Further studies will be needed using more larger scales and more objective data to confirm the effectiveness of pharmacopuncture therapy and to generalize its application.

\section{CONFLICT OF INTEREST}

The authors declare that there is no conflict of interest.

\section{ORCID}

Dong-young Kim, https://orcid.org/0000-0002-7633-8601

Seung-hyo Hong, https://orcid.org/0000-0002-1293-2820

Soo-yeon Han, https://orcid.org/0000-0001-7934-353X

Won-young Kim, https://orcid.org/0000-0003-1186-6603

Seo-hye Oh, https://orcid.org/0000-0002-9770-7381

Hyung-woo Lee, https://orcid.org/0000-0001-9783-0497

Hyun-su Woo, https://orcid.org/0000-0002-4270-9152

\section{REFERENCES}

1. Road Traffic Authority [Internet]. Wonju: Traffic Accident Analysis System (TAAS); 2020 [cited 2020 Aug 27]. Available from: http://taas.koroad.or.kr/sta/acs/exs/typical.do?menuId=WEB_ KMP_OVT_UAS_ASA.

2. Yoon IJ, Oh MS, Song TW. Clinical analysis of 112 cases of traffic accident patients. J Orient Rehabil Med. 1998;8(1):317-32.

3. Shin HR, Park KT, Yang MH, Kim YB, Yeom SR, Kwon YD. A survey on satisfaction for Korean medicine treatments in 237 traffic injury patients. J Korean Med Rehabil. 2018;28(3):67-78.

4. The Korean Orthopaedic Association. Orthopaedics. 7th ed. Seoul: ChoiSin Medical Publishing Co.; 2013. p. 1346, 1368.

5. Korean Pharmacopuncture Institute Science Committee, Pharmacopuncture Medicine Laboratory. Pharmacopuncturology. 2nd ed. Seoul: Elsevier Korea; 2011. p. 1-32, 93-115.

6. Park KB, Shin KH, Song KH, Cho JH. The clinical study on beevenom acupuncture on neck pain by traffic accidents. J Korea 
Inst Orient Med Inf. 2005;11(2):49-56.

7. Seol H, Sin MS, Song BR, Yook TH. Effects of Jungsongouhyul Herbal Acupuncture(JSO) multi-treatment for whiplash injury by traffic accident. J Pharmacopuncture. 2005;8(1):59-65.

8. Kim KH, Choi YS, Nam DW, Kim JI, Cho KH, Choi DY, et al. A clinical study on the effect of acupuncture and bee-venom acupuncture for patients with chronic whiplash injury. J Korean Acupunct Moxib Soc. 2006;23(6):145-52.

9. Chang SY, Cha JH, Jung KH, Lee TH, Hwang HS, Yoo JS, et al. The clinical study of herbal acupuncture for neck pain caused by whiplash injury. J Korean Acupunct Moxib Soc. 2007;24(4):3541.

10. Song BY. A clinical study on the effects of sweet bee venom herbal acupuncture for patients with whiplash injury. J Pharmacopuncture. 2007;10(3):77-83.

11. Im JG, Lee JB, Lee HG, Yook TH, Kim JU. Effects of the acupuncture therapy in combination with Soyeom pharmacopuncture therapy on acute whiplash injury by traffic accident. J Korean Acupunct Moxib Soc. 2011;28(4):9-18.

12. Woo JH, Han KW, Kim ES, Lee SJ, Lee JS, Nam JH, et al. A clinical study comparing the effects of Chuna treatment and Ouhyul herbal acupuncture on the patients with cervical pain caused by traffic accidents. J Korean Acupunct Moxib Soc. 2011;28(5):918.

13. Lee SJ, Lee JS, Woo JH, Kim ES, Han KW, Kim KW, et al. Case series of the effect of cervical facet joint bee-venom acupuncture for 10 patients with whiplash injury. J Orient Sports Med. 2011; 11(1):41-7.

14. Lee JH, Kim JS, Yang KY, Han SY, Lee CR, Shin HK. The comparative study on the effect of pharmacopuncture treatment and Chuna treatment for neck pain caused by traffic accidents. J Orient Rehabil Med. 2012;22(1):75-83.

15. Lim GM, Wi DY, Lee JH, Ko YS. The effects of Soyeom and Jungsongouhyul pharmacopuncture on whiplash injury by traffic accident. J Orient Rehabil Med. 2012;22(2):185-92.

16. Lee JS, Lee SJ, Nam JH, Kim KW, Lee MJ, Lim SJ, et al. The comparative study on the effect of pharmacopuncture treatment, Chuna treatment, pharmacopuncture-Chuna cooperative treatment for neck pain caused by traffic accidents. J Korean Acupunct Moxib Soc. 2012;29(5):87-95.

17. Kim TH, Park WH, Cha YY. A retrospective study on the effects of ShinBaro pharmacopuncture and Jungsongouhyul pharmacopuncture on whiplash injury by traffic accident. J Korean Med Rehabil. 2013;23(4):1-7.

18. Kim KW, Lee MJ, Jun JY, Lim SJ, Lee CH, Kim HS, et al. The comparitive study on the effect of Shinbaro pharmacopuncture and bee venom pharmacopuncture treatment of patient diagnosed as cervical disc hermiation based on the MRI after traffic accident: a retrospective, case series observational study. Acupuncture. 2014;31(1):43-50.

19. Lee YC, Nam DJ, Huh G, Lee JE, Kim B, Song EM, et al. The comparative study on the effect of HWANGRYUNHAEDOKTANG pharmacopuncture and essential bee venom pharmacopuncture for cervical pain caused by traffic accidents: a randomized controlled trial. J Korean Med Rehabil. 2014;24(4):145-53.

20. Choi JW, Chung JH, Yoon YU, Cheong SH, Lee CR. Case report of a patient with cervical syndrome caused by whiplash injury in traffic accident. J Sports Korean Med. 2015;15(1):55-64.

21. Han KI, Jeon YT, Sin SH, Lee JH, Ko YS. The retrospective comparative study on the effect of muscle relaxation pharmacopuncture and Chuna manual therapy for neck pain caused by traffic accidents. J Korea Chuna Man Med Spine Nerves. 2016;11(1): 25-32.

22. Kim YJ, Kim TR, Woo CH, Shin BC. Comparative effectiveness of Hwangryunhaedok-tang pharmacopuncture, essential bee venom pharmacopuncture and Jungsongouhyul pharmacopuncture for cervical pain caused by traffic accidents: a retrospective observational study. J Korean Med Rehabil. 2018;28(2):83-9.

23. The Korean Orthopaedic Association. Orthopaedics. 6th ed. Seoul: ChoiSin Medical Publishing Co.; 2006. p. 55.

24. Lee JH, Ahn KH, Kim HS, Kim DH, Lee KT, Yoon JS. The effect of cervical facet joint injection in patients with whiplash injury. J Kyung Hee Univ Med Cent. 2005;21(2):200-4.

25. Shin JH, Oh MS. The retrospective analysis of 1,162 traffic accident inpatients in Korean medicine hospital. J Korean Med Rehabil. 2013;23(4):233-50.

26. No BR, Lee EY. The clinical study on 34 admission patients due to sequela of traffic accident. J Pharmacopuncture. 2006;9(2): 129-34.

27. Moon MS, Kim I, Han IH. A clinical study of cervical spondylosis. J Korean Orthop Assoc. 1973;8(1):29-38.

28. Park JY, Yun KJ, Choi YJ, Kim MS, Jeon JC, Lee TH, et al. Comparative study of treatment effect between near acupuncture point needling and near acupuncture with remote acupuncture point needling on treatment of posterior neck pain. J Korean Acupunct Moxib Soc. 2011;28(1):85-92.

29. Kang JH, Jang SG, Lee H, Lee BR. The clinical study on 37 cases of whiplash injury patients which caused by traffic accident. J Korean Acupunct Moxib Soc. 2002;19(3):180-91.

30. Lee HJ. An introduction to pharmacopuncture. Seoul: Iljungsa; 1999. p. 71-91.

31. Lee JD. Bee-venom theraphy- method of clinical approach. J Korean Orient Med. 2000;21(3):3-8.

32. Lee JS, Lee JY, Kwon KR, Lee HC. A study on allergic responses between bee venom and sweet bee venom pharmacopuncture. J Pharmacopuncture. 2006;9(3):61-77. 
33. Seol H, Yook TH. Effects of Hwangryunhaedoktang herbal-acupuncture at G21(Kyonjong:肩井) on the Heart Rate Variability. J Acupunct Res. 2004;21(6):37-50.

34. Lee DH, Nam JS, Jeong HS, Jang IS, Seo ES. Two cases of grade four pressure ulcer patients treated with pharmacopuncture Soyeom and herbal medicine Taklisodok-eum. Korean J Orient Int Med. 2010;31(2):388-394.

35. Kim DW, Kim Y, Shin JS. The clinical effect of Cheongpa-jeon on the group of patients who were treated under conservative remedies for LBP(Low Back Pain). J Korea CHUNA Man Med. 2004;5(1):85-92.

36. Bae YH, Jeon JY, Lim SJ, Lee CH, Kim HS, Kim HS, et al. The case reports of muscle relaxation pharmacopuncture for the two patients with Fibromyalgia. J Korea Chuna Man Med Spine Nerves. 2014;9(2):57-68. 